University of Louisville

ThinkIR: The University of Louisville's Institutional Repository

1937

\title{
The skeletal, muscular, vascular, and the digestive systems of the ferret (Mustela putorius) and a comparison of these systems with those of the domestic cat (Felis domesticus).
}

Arthur Pincus Skwerer

University of Louisville

Follow this and additional works at: https://ir.library.louisville.edu/etd

Part of the Animal Sciences Commons

\section{Recommended Citation}

Skwerer, Arthur Pincus, "The skeletal, muscular, vascular, and the digestive systems of the ferret (Mustela putorius) and a comparison of these systems with those of the domestic cat (Felis domesticus)." (1937). Electronic Theses and Dissertations. Paper 1953.

https://doi.org/10.18297/etd/1953

This Master's Thesis is brought to you for free and open access by ThinkIR: The University of Louisville's Institutional Repository. It has been accepted for inclusion in Electronic Theses and Dissertations by an authorized administrator of ThinkIR: The University of Louisville's Institutional Repository. This title appears here courtesy of the author, who has retained all other copyrights. For more information, please contact thinkir@louisville.edu. 
THE SIELETAL, MTSCULAR, VASCUIAR, AND THE DIGESTIVE SYSTEISS OF MHE FERRET (IMUSTELA PUTORIUS) AID A COMPARISON OF THESE SYSTENS WITH THOSE OF THE DOESTTC CAT (FEITS DONESTIGUS).

\author{
A Dissertation \\ Submitted to the Faculty \\ of the Graduate School of the University of Louisville \\ In Partial Fulfillment of the \\ Requirements for the Degree \\ of Master of Science
}

Department of Biology

By

Arthur Pincus Skwerer 


\section{ACKNOWTEDGIIENTS}

I am indebted to Dr. H. B. Lovell, under whose supervision the study has progressed, for his guidance and numerous suggestions which at all times proved very valuable.

I wish to thank Dr. P. A. Davies for his helpful criticism and for extending to me the facilities of the Department of Biology.

I wish to thank Dr. Ralph Ioring, Department of Physics, who personally prepared all of the photographic reproductions contained in this paper. 
Arthur Pincus Skwerer

THE SKELETAI, MUSCULAR, VASCULAR, AND THE DIGESTIVE SYSTEMS OF THE FERRET (MUSTELA PUTORIUS) AND A COMPARISON OF THESE SYSTEMS WITH THOSE OF THE DOMESTIC CAT (FELIS DOMESTICUS).

Thesis Director: Dr. Harvey B. Lovell

Approved By:-

Reading Committee

1. P. A. Davies

2. J. B. Rogers

3. William McCay

4.

Harvey B. Lovell

Representative of the English Department:

Mary Burton

JUNE 1937. 


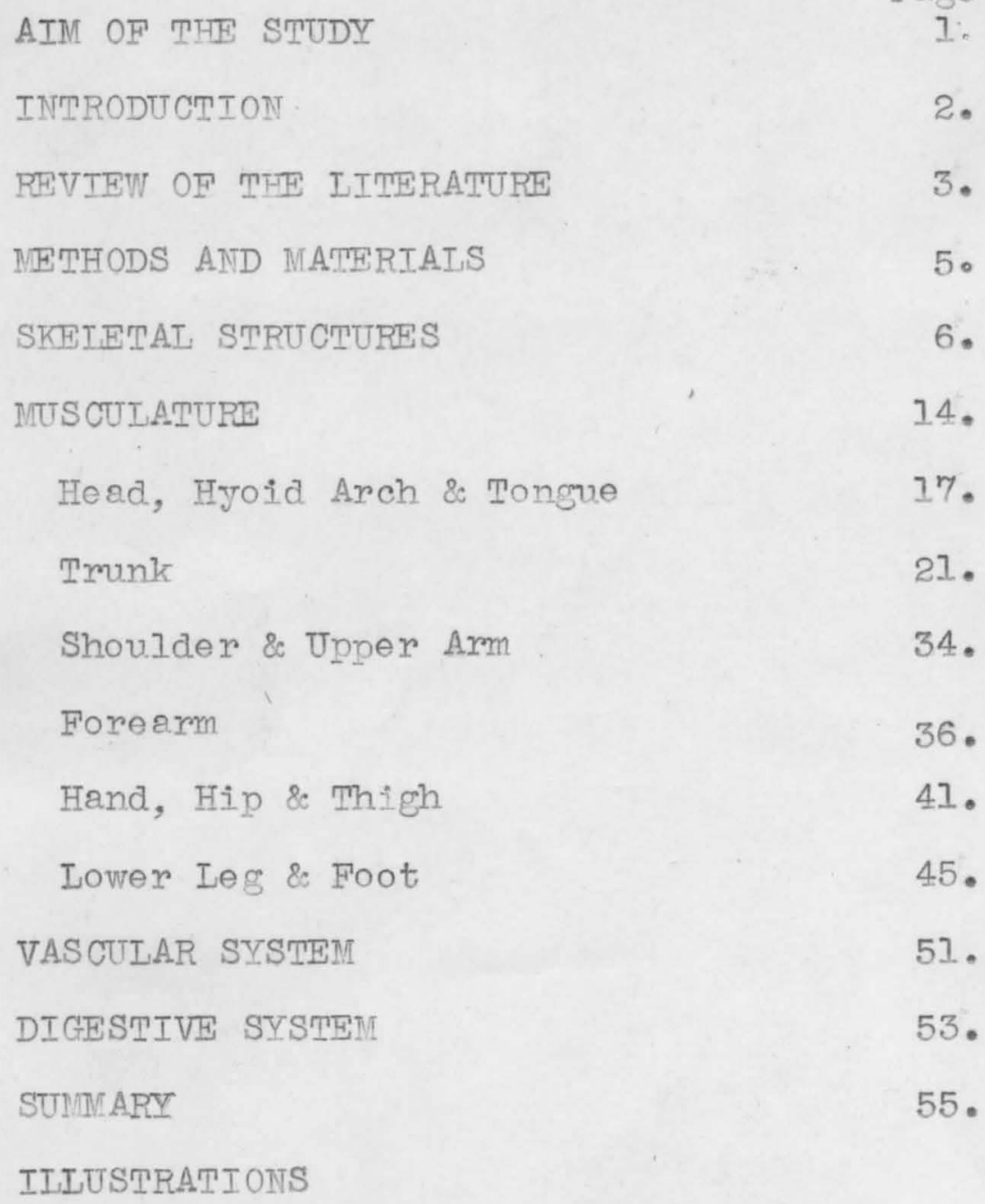




\section{AIM OF THE STUDY}

The aim of this study on the ferret (Nustela putorius) is to compare the anatomy, of the sireleton, the musculature, the vascular system and the digestive system, of the ferret with the homologous structures of the domestic cat (Felis domesticus). Although the ferret has been used extensively in experimental work, there are few references related to its anatomy. Because of its importance as a laboratory animal, it is hoped that this dissertation will be of some value to those who need to know the ferret's anatomy for experimental purposes and to the anatomist who may be interested in its comparat1ve structure. 


\section{INTRODUCTION}

The ferret (Mustela putorius) is a slender animal about fourteen inches in length. It resembles the mink or the weasel in having a pointed nose, a small head, a long neck, and a long slim body. In dorsal. view its skull resembles an isosceles triangle. Ferrets are often classified into two varieties upon the basis of coat color: The albino, which is pink-eyed, and has a yellowish fur, and the fitchet type, which has short, yellow fur next to the slrin and a longer covering of black hair. The fitchet's eyes are very dark. The ferret appears to crawl with its anterior extremity lower than its posterior extremity because its appendages are relatively short, and the hindlimbs are longer than the forelimbs. The tail, which is mobile but not prehensile, is approximately five inches in length. For protection the ferret has a pair of relatively large anal glands which secrete a foetid substance. The ferret is a musteline mammal and a true carnivore but some doubt exists as to whether it is a distinct form or merely a domesticated variety of the European Polecat (Mustela putorius). However, because of the similarity in life cycles and outward appearances 
of the European Polecat and the ferret, the generally accepted view is that they are different varieties of the same species.

\section{REVIEW OF THE IITERATURE}

The literature contains numerous articles dealing with the ferret. The earliest reference which could be found is a book by Edwards (1853) in which is given a brief account of the ecology and genealogy of this mammal. The first anatomical study on the ferret is Alix's "Memoire sur la myologie du Putois" (1876). In this paper is given an extensive description of the polecat's musculature. Robinson (1893) published his observations on the early development of the ferret. Everitt (1897) discusses the methods used in breeding ferrets and the uses of these animals in hunting and rodent extemination. During 1897 and 1898 articles by Windle and Parsons appeared. These authors reviewed the muscular anatomy of a group of terrestrial carnivores, including the ferret. It was not until 1904, when Marshall published his first paper on the sexual cycle of the female ferret, that this carmivore became popular as an experimental animal. Harding (1915) a breeder, 
discussed methods of caring for ferrets. Robinson (1918) discussed the formation and rupture of the ferret's ovarian follicle. Pitt (1921) reported on the genetic behavior of the ferret's coat color and skuli morphology. Marshall (1922) in his book "Physiology of Reproduction" discusses the ferret's sexual cycle. Laidlaw and Dunkin (1928) published. a paper on distemper in the ferret. In 1929 Dunkin, Laidlaw, and Griffith discussed tuberculosis in this cernivore. Marshall and Hammond (1930) published a paper on the female ferret's sexual cycle. Mainland (1930, 1931a, 1931b, 1931c, 1931d, 1931e, 1932) made a series of studies on the ferret's early development. Hill and Parkes (1930) reported. on their method of inducing ovulation in the ferret. Dalling (1931) discussed distemper in the fitchet. A series of articles on the male ferret's sexual cycle were then published. The first of these is by Allanson (1932) while other articles were written by Bissonnette (1933, 1935a, 1935b). The ferret is widely used in experiments on human influenza. Smith, Andrewes, and Laidlaw (1935) discussed immunization of ferrets to this disease. Shope (1934) reported on his work with the ferret on influenza. 


\section{INETHODS AND MATERIALS}

The animals used in this work were secured from $\mathrm{Mr}$. Levi Farnsworth, a breeder in New London, Ohio. A study was made of their external anatomy. They were killed by illuminating gas. The specimens were embalmed with the following fluid:

$$
\begin{array}{ll}
\text { Glycerin (comercial) } 500 \mathrm{c.c} . \\
\text { Formalin (comercial) } 150 \mathrm{c.c} . \\
\text { Phenol (comercial) } 500 \mathrm{c.c} .
\end{array}
$$

In order to keep the muscles pliable the animals were immersed in the embalming fluid. In studying their internal anatomy special attention was paid to the musculature and to the bones. A previously dissected specimen of the cat (Felis domesticus) was used for comparison, and deviations of structures in the ferret from those of the cat were noted. Outline drawings of most of the bones of the ferret were prepared and the areas of attachment of the muscles on these bones were show by shading the outlines.

1

Reighard, J., and H.S.Jennings, 1935. Anatomy of the cat (ed. 3, revised; Henry Holt and Company), was used to identify the structures of the cat. 
SKETETAT STRUCTURES

The skeletal stmcture of Mustela putorius has received scant attention. With the exception of an article by Pitt (1921), in which the skulls of the European Polecat and the ferret are compared, ther are no references to its skeleton in the literature.

The ferret's sizulI (Plate VI, Fig. 2) appears more primitive than that of the domestic cat. It is long in proportion to its width, the brain-case is flat and narrow, and the foramen magnum is slightly more caudal in position than that of the cat. Several features of the ferret's skull which are characteristic of carnivores are: (1) the lack of fenestrae, (2) the relatively thick bones, and (3) the closely knitted. sutures which are often obliterated, as is the one between the parietal and the temporal bones. These characteristics are correlated with the carnivores' predacious habits. In the ferret the orbital and the temporal fossae are continuous, and are only slightly separated from each other by the zygomatic process of the frontal bone and the frontal process of the malar bone. This is unlike the condition in the cat where the latter two processes are more prominent and partly separate the two fossae. Because the ejes of the ferret 
are relatively small, the orbital fossa is reduced and is much smaller than the temporal fossa. In the domestic cat the orbital fossa is larger than the temporal fossa. In the ferret the sagittal crest is more prominent than in the domestic cat and it extends forward along the median dorsal line from the lambdoidal ridge to the posterior end of the frontal bones. The hard palate is relatively longer in the former than in the cat due to the elongation of both the maxilla and palatine bones, and extends about one centimeter caudad to the last molar. The tympanic bulla is flattened, and is nearly rectangular in shape, although broadening slightly caudad. This reduces the size of the cavity of the midale ear.

The ferret's teeth are typically carnivorous, that is, the premolars and molars are thin and elongated. In this respect they are similar to those of the domestic cat. However, the last molar in the ferret's upper jaw is elongated transversely and has two broad, flattened cusps. The homologous teeth in the cat are not flattened. These two animals also differ in their dental formulae. The dental formula for the ferret is: I $3 / 3$, C $1 / 1$, PM $3 / 3$, $\mathbb{M} 1 / 2 .^{2}$ That for the cat is I $3 / 3, \mathrm{C} I / 1, \operatorname{PM} 3 / 2, \mathbb{M} 1 / 1$.

2 The tooth formula for the ferret has been prepared from observations made upon mature specimens. No studies upon the development of the teeth to check the relative number of premolars and molars have been made. 
The former has 34 teeth, four more than are found in the domestic cat. The additional teeth in the ferret are accomodated in the mandible, which is composed of two bones. Each half consists of a horizontal portion, the body (which bears the teeth on its alveolar border) and of a vertical portion, the ramus. The body is similar to that of the cat in being in the form of a flattened cylinder having two surfaces (a lateral, and a medial one) and two borders (a dorsal or alveolar, and a ventral border). However, the diastema, which is a constant feature in the domestic cat, has been obliterated in order to accomodate the additional teoth in each side of the ferret's lower $j$ ow. The ramus is divided into two portions, the coronoid process and the condyloid process. But, in the ferret the coronoid process extends dorsad whereas in the cat it extends dorsocavdad. The condyloid process is a semi-cylindrical transverse bone attached to the caudal margin of the coronoid process. The scapula of Mustela putorius (Plate I, Fig. 1) and Felis domesticus differ in several respects. The infraspinatus fossa in the cat is larger than the supraspinatus fossa. In the ferret the reverse condition exists. The coracoid process, which is relatively prominent in the cat is virtually absent in the ferret. . However, the coracoid bone, fused to the scapula, forms a projecting dorsal portion of the glenoid fossa in 
Mrustela putorius. The acromion process of the domestic cat is relatively more prominent than that of the ferret. The lengths of the anterior and vertebral borders of the cat's scapula are practically equal, whereas the anterior border of the ferret's scapula is much shorter than the vertebral border. In the latter the vertebral border is sharply curved at the point where the spinous process ends. This forms an aditional angle not found in the cat. It is here named for convenience, the spinal angle. It is due to these features that the ferret's scapula has a narrower and a longer appearance than that of the cat. The cat's scapula is practically hemispherical in form.

The clavicle, which is often missing in the higher manmals, especially those which use their limbs for fast running, is rudimentary in Mustela putorius. However, it is well-developed though small in the domestic cat just as in the more primitive forms, and those forms which are specialized for tree climbing and digging.

With several slight exceptions the vertebral. column of the domestic cat and that of the ferret is similar in constmetion. In the cat, that part of the lateral mass of the atlas which bears the articular facet 
projects craniad of the dorsal arch, and is separated from the transverse process by a deep triangular notch. Along the bottom of this notch runs a groove which connects the cranial end of the formen transversarium and the atlantal formen. In the ferret's atlas this groove is closed laterally, forming a foramen in the transverse process laterad of the foramen transversarium. This foramen, here named for convenience, the lateral transverse foramen, is connected with the atlantal formen by a shallow groove. This is apparently a remnant of the larger groove in the atlas of the cat. There are no differences in the construction of the other cervical vertebrae except that the transverse processes and the processes costarii are more definitely differentiated, in the cat than in the ferret. As in most of the mammals, there are seven. cervical vertebrae. Since the ferret has fourteen pairs of ribs, there is a corresponding number of thoracic vertebrae. In the cat there are only thirteen rib-bearing vertebrae. The spinous processes of the first four thoracic vertebrae of the cat are of about the same length. They then decrease in length to the twelfth, while the twelfth and the thirteenth are slightly longer than the eleventh. In the ferret the first four thoracic spinous processes are also approximately equal in length but the 
remainder gradually decrease in height. There is no increase in hoight in the region of the twelfth or thirteenth vertebrae as in the cat. No differences in the structure of the Iumbar nor of the sacral vertebrae were observed. The caudal vertebrae of both of these forms are also similar in construction but those of Mustela putorius number twleve or thirteen, whereas those of the domestic cat are usually twenty-one to twenty-three in number. This is to be expected because the former's tail is relatively much shorter than that of the latter. The skeletal structures of the extremities of the ferret and the domestic cat differ but slightly in form and in relative length. The humeri of both of these forms are nearly identical in appearance. However, the medial epicondyle in the ferret is larger, the greater tuberosity is more pronounced, and adjacent to the olecranon fossa there are two smaller fossae which are not. present in the humerus of the domestic cat. One of them, which is proximal to the olecanon fossa, accomodates the proximal tip of the olecranon process. The function of the other fossa, which is lateral to the olecranon fossa could not be ascertained. In the cat these additional fossae probably have merged with the olecranon fossa, for here it is relatively more extensive than in the ferret. The radii and the ulnae of the ferret (Plate III, Figs. I \& 2) and those of the cat are also similar. 
However, in the ferret the u.lna and the humerus are of equal length whereas in the domestic cat the ulna is appreciably longer than the humerus.

There are several minor differences in the structure of the femur in the ferret (Plate IV, Figs. I \& 2) and in the cat. In the domestic cat the neck of the femur is clearly demarcated from the head but not as sharply as in Mustela putorius, where the neck is more slender. The shaft of the ferret's femur is relatively more slender than that of the cat. In addition, the cat's femoral shaft is cylindrical in form, whereas in the ferret it is narrower at the middle and broader at the extremities. No marked differences have been noted. in the structure of the tibiae and the fibulae of these animals. The distal portions of the extremities of these animals are also similar with the exception of the metatarsals of the pelvic apnendages. The ferret has five metatarsals on its hindlimb whereas the cat has only four and the rudiment of a medial metatarsal. Although in the cat the hindlimb is slightly longer than the forelimb, there is a greater difference in the length of the limbs in Mustela putorius. As a result the ferret walks with the posterior part of the body higher than the anterior part.

The innominate bones of the domestic cat and the ferret have the same general appearance (Plate VI, Fig. 1) but they differ in several details. The innominate 
of the latter is relatively much longer than that of the former. However, the ischio-pubic symphysis in the ferret is much shorter than in the domestic cat. This changes the shape of the obturator foramen. It is elongated in a dorso-cephalad and ventro-caudad. direction in the ferret, but is almost round in the cat. The avricular impression in the fomer is subdivided into a dorsal and ventral portion which articulates with corresponding portions of the sacrum. In the cat the impression is crescentic. The iliopectineal eminence is much more pronounced in the ferret than in the cat.

From the above comparisons of the skeletal structures of the ferret and the domestic cat, it is evident that the structure of the skulls is the most distinctive and therefore of greatest value in classifying these carnivores. The skull of each is distinctly different and it is impossible to mistake one for the other. Because of the structure and relations of the orbital and temporal fossae, and the smaller brain-case in the ferret, the writer would place it lower in the order of carnivores than the domestic cat. 


\section{NUSCUIATURE}

The ferret's musculature, which is identical with that of the European polecat, was dissected with the assistance of Alit's (1876) "Nemoire sur la Nyologie du Putois". The domestic cat (Felis domesticus) was used for comparison, and any apparent differences between it and the ferret (Mustela outorius) were recorded. As dissection proceeded, the points of attachment of the muscles to the bones were noted. Outline drawings of the bones (see plates) were made and then shaded to show the places of muscle-attachment.

The musculature of the ferret (Mustela putorius) presents several variations from that of other carnivores. Perhaps the most unique of these is the presence of a fourth, angular head to the Triceps Brachii muscle. Windle and Parsons (1897-1898) have appropriately suggested. that in such cases the muscle be known as the Quadriceps Brachii. After making a comparative study of the myology of seven families of the carnivores, these authors concluded that this condition is peculiar only to one of 3 these, the Nustelidae. However, the Nustelidae is not the

3

The seven families are: the Felidae, the Hyaenidre, the Viverridae, the Canidae, the Ursidae, the Procyonidae, and the Mustelidae. 
only group in which this peculiarity has been observed. It has been reported as being present in man, but here the condition is rare and anomalous, whereas in the ferret the feature is constant. ${ }^{4}$ The Coracobrachialis muscle, which in the cat serves to adduct the humerus, is not present in the ferret. Comparison of the Sterno-mastoid muscles of both of these animals revealed that unlike the condition in the cat the muscles of the opposite sides in the ferret fuse in the midine. Windle and Parsons (1897-1898) reported that this condition has never been found among the Felidae. The complete absence of the Serratus Posterior Inferior muscle in the ferret is another immedately apparent deviation from the cat's myology. The Rectus Capitis Posterior Minor muscle which assists the Rectus Capitis Posterior Major in raising the snout is represented by a few fibers in the ferret. The homologous muscle in the domestic cat is a distinct triangular bunde. In correlation with the apparent absence of the clavicle the muscles of the shoulder region in the ferret have a slightly altered arrangement. In the domestic cat none of the Pectoralis muscles insert to the clavicle, but in the ferret, part D (page 29) of this group inserts to the clavicle's maiment. The ferret's Clavo-trapezius muscle.

4 Anatomy of the Human Body. Gray. 22nd Edition. 1930. p. 443. Lea \& Febiger, N. Y. 
is inserted to the deltoid raphe as well as to the manubrium of the sternum but in the domestic cat this muscle does not send any fibers to the sternum. In both the ferret and the cat the insertions of the Cleidomastoideus muscle is the same, that is, to the Clavotrapezius muscle. Other variations in structure, such as the point of insertion of the Pronator Teres muscle, may be mentioned. It inserts to the middle of the radius in the Felidae and at the lower end of the radius in the Minstelidae. Very often such differences in structure are not constant and should not be relied upon entirely as criteria for classification. 
MUSCIES OF THE HEAD, HYOID ARCH, AND TONGUE.

DIGASTRICUS (Ie Digastrique)

Origin: From the medio-ventral border of the posterior half of the mandible (Plate I, Fig. 2).

Insertion: To the latero-posterior aspect of the tympanic bulla and to the area of the skull bounded by the mastoid process and the bulla.

MASSETER (Ie Nasseter)

Origin: From the zygomatic arch (Plate VI, Fig. 2). Insertion: To the ventral margin of the mandible at its posterior one-third and to the lateral surface of the mandible (Plate I, Fig. 2).

TEMPORAIIS (Le TemporaI)

Origin: From the entire temporal fossa.

Insertion: To the coronoid process of the mandible (Plate I, Fig. 2).

5

The French names are those used by Alix (1876) in his description of the myology of the Polecat. His nomenclature does not agree in every instance with the Latin terms used at present. He often resorts to descriptive French terminology• The modern homologues for the French terms should be useful to present workers. 
PTERYGOIDEUS (This muscle was not mentioned by Alix)

Origin: From the external surface of the palatine bone in two parts.

Insertion: To the upper part of the internal surface of the ramus of the mandible and to the mandible near its angle (Plate I, Fig. Z).

THYREOHYOIDEUS (Ie ThyYo-hyoidien)

Origin: From the lateral border of the thyreoid. cartilage.

Insertion: To the caudal hom of the hyoid.

OMOHYOIDEUS (I'omo-hYoidien)

absent.

GENIOHYOIDEUS (Ie Genio-hyoidien)

Origin: From the mandibular symphysis (Plate I, Fig. 2).

Insertion: To the basihyal bone.

STYLOHYOIDEUS (Le Stylo-hyoidien)

Origin: From the external surface of the stylo-hyal bone.

Insertion: To the body of the hyoid.

IONGUS CAPITIS (Ie Grand Droit Anterieur de Ia Tete)

Origin: From the ventral aspect of the transverse 
processes of all the cervical vertebrae from the axis to the sixth vertebra.

Insertion: To the base of the occiput.

\section{ILI0-COSTALIS (Un faisceau du sacro-lombaire)}

Origin: From the Iongissimus Dorsi muscle and the ribs.

Insertion: The muscle is composed of several bundes each of which inserts to the ventro-lateral aspect of the 2nd, 3rd, or 4 th rib craniad of its origin.

\section{SPINALIS DORSI (Ie Iong Interspinale)}

Origin: Neural Spines of Vertebrae.

Insertion: Neural Spines of Vertebrae.

This muscle connects the neural spines of all of the vertebrae from the elventh thoracic as far forward as, and including the sixth cervical vertebra.

INTERSPINAIES AND INTERTRANSVERSARII

(Ies Interepinevx et les Intertransversaires)

The Interspinales have the usual arrangement. They connect contiguous spinous processes. This is also true of the Intertransversarif which connect the transverse processes.

SPLENIUS (Ie Splenius)

Origin: From the spinous processes of the first three thoracic vertebrae and from the dorsal midline as far forward 
as the axis, by fascia.

Insertion: To the occipital crest and also to the base of the mastoid process.

CIEIDOMASTOIDEUS (Ie Cleido-mastoidien)

Origin: From the mastoid process by tendon.

Insertion: To the deltoid raphe on the deep

surface of the Clavo-trapezius muscle.

OMOTRACHEIIAN (I,Acromio-atIoidien)

Origin: From the ventral aspect of the transverse process of the AtIas.

Insertion: To the metacromion process of the scapula (Plate I, Fig. I).

IATISSINUS DORSI (Ie Grand Dorsal)

Origin: From the mid-dorsal line extending from the eighth to the fifteenth vertebra. Also from the tenth to the twelfth ribs.

Insertion: To the humerus with the Teres Major and also to the internal aspect of the humems with the Pectoralis Major( Plate II, Fig. 2).

IEVATOR ANGUII. SCAPULAE AND SERRATUS IMAGNUS

(I'Angulaire de I'Omoplate et le Grand. Dentele)

Origin: From the transverse processes of the last three cervical vertebrae and from the first six ribs. 
Insertion: To the angle of the scapula and also to its caudo-axial border (Plate I, Fig. I).

MYLOHYOIDEUS (Le Milo-hyoidien)

Origin: From the medial surface of the mandible from the symphysis to the mandibular foramen (Plate I, Fig. B).

Insertion: To the median raphe extending from the mandibular syphysis to the basihyal.

\section{HYOGLOSSUS (Ie Hyo-glosse)}

Origin: From the basihyal bone.

Insertion: To the tongue by muscular fibers. Its origin is laterad of that of the Genioglossus muscle.

GENIOGLOSSUS (Ie Genio-glosse)

Origin: From the symohysis of the mandible.

Insertion: To the tongue.

\section{STYLOGLOSSUS (Ie Stylo-glosse)}

Origin: From the stylohyal and from the ventral surface of the tympanic bulla.

Insertion: To the tongue. It merges with the Hyotglossus muscle at its insertion.

\section{MUSCLES OF THE TRUNK}

SPINO-TRAPEZIUS (Un faisceau du Trapeze)

Origin: From the ventral aspect of the transverse process of the atlas. 
Insertion: To the superior fifth of the spine of the seapula on its caudal aspect (Plate I, Fig. I). ACRONI0-TRAPEZIUS (Un faisceau du Trapeze).

Origin: From the occipital crest and also from the dorsal midline by fascia.

Insertion: To the ridge of the scapular spine as far as the base of the acromion process (PIate I, Fig. I).

CLAVO-TRAPEZIUS (Un faisceau du Trapeze)

Origin: From the occipital crest.

Insertion: To a raphe between the Clavo-trapezius and the Clavo-deltoid muscles. It also inserts some fibers to the manubrium of the sternum.

RHOMBOIDEUS CAPITIS (Ie Rhomboide de la tete)

Origin: From the lambdoidal crest. Insertion: To the angle of the scapula with the Rhomboideus Cervicalis (Plate I, Fig. I).

RHONBOIDEUS CERVICAIIS (Ie Rhomboide)

Origin: From the dorsal midline extending from the second to the eighth vertebrae.

Insertion: To the angle of the scapula with the Phomboideus Capitis (Plate I, Fig. I). 
COMPIEXUS MAJOR (Le Grand Complexus)

This muscle is divisible into the Biventer Cervicis and the Complexus.

Biventer Cervicis

origin: From the posterior articular processes of the fifth, sixth, seventh, and eighth vertebrae.

Insertion: To the lambdoidal crest.

Complexus

Origin: From the posterior articular processes of the fifth, sixth, seventh, as well as the third and the fourth cervical vertebrae.

Insertion: To the lambdoidal crest. It lies laterad of the Biventer Cervicis and is closely fused to this muscle.

RECTUS CAPITIS POSTERIOR MAJOR (Ie Grand Droit POsterieur)

Origin: From the neural spine of the axis.

Insertion: To the occiput beneath the lambdoidal ridge.

RECIUS CAPITIS POSTERIOR MEDIUS (IE Moyen Droit)

Origin: From the anterior portion of the axial spine. Insertion: To the occiput ventral to the insertion of the Rectus Capitis Posterior Major. 
RECTUS CAPITIS POSTERIOR MINOR (IE Petit Droit Posterieur)

It is represented by a few muscle fibers which mun from the atlas to the occiput. It is immediately subjacent to, and more or less fused with, the Rectus Capitis Posterior Medius muscle.

OBIIQUUS INFERIOR (Ie Grand Oblique)

Origin: From the lateral surface of the neural spine of the axis.

Insertion: To the dorsal surface of the transverse process of the atlas.

OBIIQUUS CAPITIS SUPERIOR (Ie Petit ObIique)

Origin: From the transverse process of the etlas. Insertion: To the occiput. It is a small, fleshy muscle.

EXTENSOR CAUDAE IEDIAIIS (Ie Sacro-coccygien Superieur)

Origin: From the spinous processes of the lumbar, saeral, and first caudal vertebrae.

Insertion: To the articular processes and dorsal surfaces of the caudal vertebrae.

EXTENSOR GATDAF IATERAIIS (Ie Sacro-coccygien Inferieur)

Origin: From the articular processes of the sacral and the transverse processes of the caudal vertebrae.

Insertion: To the dorsal surfaces of the caudal vertebrae. 
IONGISSTMUS DORSI (Le Long de Dos)

Origin: From the dorsal surface of the sacrum and from the spinous processes of the Iumbar and lower thoracic vertebrae. It becomes differentiated from the Spinalis Dorsi (which lies medial to it) at the level of the seventh thoracic vertebrae.

Insertion: By tendons which bifurcate. One end. inserts to the transverse process of each of the thoracic vertebrae. The other end of each of these tendons inserts to the tuberosity of the corresponding rib (with the exception of the last three ribs). There are also insertions to the last three cervical vertebrae. This muscle is connected to the Ilio-cosatalis muscle by the lumbo-sacral fascia.

COMPIEXUS MINOR (Le Petit Complexus)

origin: From the posterior articular processes of the fourth, fifth, and sixth cervical vertebrae.

Insertion: To the lambdoidal crest.

ABDUCTOR CATDAE EXTERNUS (Not named by Alj.x)

Origin: From the medial surface of the ilium.

Insertion: To the transverse processes of the caudal vertebrae. 
ABDUCTOR CAUDAF INTERNUS (I'Ischio-coccygiens)

Origin: From the spine of the ischium.

Insertion: To the transverse processes of the first three caudal vertebrae.

\section{IIIO-CAUDAIIS (I'IIio-coccygiens)}

Origin: From the ventral half of the medial aspect of the ilium.

Insertion: To the ventral surfaces of the first to third caudal vertebrae.

FIEXOR CAUDAE LONGUS (Not named by AIiX)

Origin: From the ventral surface of the sacrum. Insertion: To the ventral faces of the caudal vertebrae.

FIEXOR CAUDAE BREVIS (Not named by Alix)

Origin: From the ventral face of the first caudal vertebra.

Insertion: To the ventral surfaces of the caudal vertebrae.

\section{IIIOPSOAS (Ie PSOaS Iliague)}

Origin: From the ventral surfaces and transverse processes of the lumbar vertebrae and from the last two thoracic vertebrae.

Insertion: To the lesser throchanter of the femur (Plate II, Fig. $\mathbf{I}$ ). 
QUADRATUS IUMBORUM (Ie Carre des Iombes)

Origin: From the extermal border of the Psoas Minor. Insertion: $T_{0}$ the crest of the ilium.

PSOAS MINOR (Ie Petit PSOaS)

Origin: From the internal border of the Psoas Iiajor. Insertion: To the ilio-pectineal eminence.

STERNOMASTOIDEUS (Ie Stemomastoidien)

origin: From the manubrium of the sternum.

Insertion: To the mastoid process. It fuses with the muscle of the opposite side.

STERNOHYOIDEUS (Ie Sternohyoidien)

Origin: From the dorsal surface of the manubrium of the sternum.

Insertion: To the basihyal.

STERNOTHYROIDEUS (Le Sternothyroidien)

Origin: From the dorsal aspect of the manubrium of the sternum.

Insertion: To the thyreoid cartilage.

SCAIENUS (Ie Scalene Posterieur et Anterieur)

Origin: From the transverse processes of all the cervical vertebrae. 
Insertion: In four parts: To the third and fifth ribs; to the middle of the first rib; to the third rib laterad of the previous insertion on this rib; to the cranial aspect of the first rib.

RECTUS GAPITIS ANTERIOR (Ie Petit Droit Anterieur)

Origin: From the antero-ventral surface of the transverse process of the atlas.

Insertion: To the occiput subjacent to the insertion of the Rectus Capitis Lateralis.

RECTUS CAPITIS IATERAIIS (Le Petit Droit IateraI)

Origin: From the latero-ventral surface of the transverse process of the atlas.

Insertion: To the lateral portion of the occiput.

LONGUS COIII (Ie Iong du Cou)

This muscle has two divisions, the anterior portion and the posterior portion. Anterior portion

Origin: From the ventral surface of the atlas.

Insertion: To the transverse processes and ventral surfaces of the first six cervical vertebrae following the atras.

Posterior portion

origin: From the sixth cervical vertebra. 
Insertion: To the ventral surfaces of the first six thoracic vertebrae.

PECTORAIIS (Ie Grand PectoraI)

This muscle is divisible into four parts:

A. Origin: From the stermum between the manubrium and the point of articulation of the third rib.

Insertion: To the pectoral ridge of the humerus. B. Origin: From the manubrium of the sternum.

Insertion: To the pectoral ridge of the humerus craniad of part A.

c. Origin: From the entire sternum caudad of the point of articulation of the third rib.

Insertion: To the proximal half of the humerus. D. Origin: From the sternum between the first and the third ribs.

Insertion: To the deltoid raphe and to the lateral tuberosity of the humerus (PIate II, Fig. 2).

SERRATUS POSTERIOR SUPERIOR (Ie Petit Dentele Anterieur)

Origin: From the ventral surfaces of the third. to the tenth ribs ventrad of their angles. Insertion: By fascia to the dorsal midline.

SERRATUS POSTERIOR INFERIOR

absent. 
TRANSVERSUS COSTARUM (Not named by Alix)

Origin: By fascia from the sternum between the first and the third ribs.

Insertion: To the first rib. It covers the insertion of the Rectus Abdominis muscle.

IEVATORES COSTARUM (IES Surcostaux)

Origin: From the transverse processes of the thoracic vertebrae.

Insertion: To the angle of each succeeding rib.

INTERCOSTAIES EXTERNI (Les Intercostaux Extermus)

Origin: From the ribs. These muscles attach to adjacent ribs and extend between these ribs.

Insertion: To the ribs. Their fibers run in a caudo-ventrad direction. They are lacking in the interspaces between the first tinee ribs where the Intercostales Interni are exposed.

INTERCOSTAIES INTERII (Les Intercostaux Internus)

These have the same arrangement as the Externi. However, the former lie internal to the latter and their fibers run in a direction nearly at right angles to that of the Externi.

TRANSVERSUS THORACICUS (Not mentioned by Alix)

Origin From the lateral margin of the inner aspect of the stermux between the third to the 
eighth ribs inclusive.

Insertion: To the cartilages of the respective ribs at their junction with the ribs.

DIAPHRAGMA (Not mentioned by Alix)

Origin: From the ventral surfaces of several of the lumbar centra by a tendon.

Insertion: To the xiphoid process and to the last five ribs. This muscle consists of three parts: Two sternocostal portions and a dorsocentral portion.

TRANSVERSUS ABDOMINIS (Not mentioned by Alix)

Origin: From all of the false ribs and from the true ribs by interdigitation with the diaphragm. Also from the transverse processes of all the lumbar vertebrae and from the anterior part of the ventral margin of the ilium.

Insertion: To the ventral midline on the linea alba.

TERES MINOR ( Le Petzt Rond)

Origin: From the axillary border of the scapula (Plate I, Fig. I).

Insertion: Immediately below the greater tuberosity of the humems (Plate II, Fig. 2).

TERES MAJOR (Ie Grand Rond)

Origin: From the axillary border of the scapula and from its angle (Plate I, Fig. I ). 
Insertion: To the medial side of the humerus with the Latissimus Dorsi (PIate II, Fig. 2).

CORACOBRACHIAIIS

Absent.

SUBSCAPULARIS (Ie Sous-scapulaire)

Origin: From the subscapular fossa (Plate I, Fig. I).

Insertion: To the lateral aspect of the medial

tuberosity of the humerus (Plate II, Fig. 2).

\section{EPITROCHIEARIS (Le Dorso-olecranien)}

Origin: From the Iatissimus Dorsi.

Insertion: To the fascia of the forearm.

\section{BICEPS BRACHII (Le Biceps)}

Origin: From the coracoid process of the scapula (Plate I, Fig. I).

Insertion: To the bicipital tuberosity of the radius (Plate III, Figs. I \& 2 ).

ACROMIODELTOIDEUS (Le Deltoide-acromial)

Origin: From the caudal surface of the acromion of the scapula (Plate I, Fig. I).

Insertion: To the deltoid ridge of the humerus (Plate II, Fig. 2). 
CLAVODEITOIDEUS (Le Deltoide Glaviculaire)

Origin: From the tendinous line of intersection between this muscle and the Clavotrapezius muscle. Insertion: To the crest of the humerus.

SUPRASPINATUS (Le Sus-epineux)

Origin: From the entire supraspinous fossa of the scapula (Plate I, Fig. I).

Insertion: To the lateral tubercle of the humerus (Plate II, Fig. 2).

- INFRASPINATUS (Ie Sous-epineux)

Origin: From the entire infraspinous fossa of the scapula (Plate I, Fig. 1).

Insertion: To the lateral head of the humems immediately distad of the Supraspinatus insertion (Plate II, Fig. 2).

OBIIQUUS ABDOMINIS EXITERNUS (Le Grand Oblique de I'Abdomen)

Origin: From all of the ribs with the exception of the first two.

Insertion: To the linea alba by aponeurosis from the xiphoid process to the pubic symphysis and to the medial portion of the anterior pubic border. 
OBIIQUUS ABDONINIS INIERINUS (Ie Petit Oblique de I'Abdomen)

Origin: From the anterior border of the ilium and.

from the lumbodorsal fascia.

Insertion: To the midventral line by thin aponeurosis.

RECTUS ABDOMINIS (Ie Grand Droit Anterieur de I'Abdomen)

Origin: From the entire pelvic symphysis.

Insertion: To the first costal cartilage by a thin tendon.

MUSCTES OF THE SHOULDER AND UPPER ARM

SPINODEITOIDEUS (Ie Deltoide Posterieur)

Origin: From the caudal aspect of the scapular spine (Plate I, Fig. I).

Insertion: To the deltoid ridge of the humerus (Plate II, Fig. 2).

BRACHIAIIS (Ie Brachial Anterieur)

Origin: From the dorso-lateral surface of the humerus (Plate II, Fig. I) distad of the tuberosity.

Insertion: To the medial side of the ulna (Plate III, Fig. I) distad of the semilunar notch by a flat tendon. 
6

CAPUT AITUII OF THE TRICEPS BRACHII (Le Tricers Brachial)

Origin: From the axillary border of the scapula

(Plate I, Fig. I) near the angle.

Insertion: To the medial aspect of the olecranon (Plate III, Fig. I) and to the forearm by fascia.

CAPUT IONGUM OF THE TRICEPS BRACHII (Ie Triceps Brachial)

Origin: From the humerus on and slightly below the epiphyseal line (Plate II, Fig. 2).

Insertion: To the posterior aspect of the olecranon and by fascia to the other bund.es of the triceps muscle.

CAPUT LATERAI OF THE TRICEPS BRACHII (Ie Tricegs Brachial)

Origin: From the axillary border of the scapula (Plate I, Fig. I) extending from the glenoid cavity to the tip of the acromion.

Insertion: To the lateral aspect of the olecranon (Plate III, Fig. 2) and also to the forearm by fascia. CAPUT NEDIATE OF THE TRICEPS BRACHII (Ie Triceps Brachial)

Origin: From the posterior aspect of the surgical neck of the humerus (PIate II, Fig. I).

Insertion: To the dorsal aspect of the olecranon process (Plate III, Fig. 2).

6

Since this muscle has four heads in the ferret, it might properly be called the Quadriceps Brachil. 
ANCONEUS (I'Ancone)

Origin: From the distal extremity of the humems on its dorsal surface (Plate II, Fig. I).

Insertion: To the dorso-lateral aspect of the olecranon.

\section{MUSCLES OF THE FOREARM}

\section{BRACHIORADIAIIS (Ie Iong Supinateur)}

origin: From the proximal portion of the dorsal margin of the supracondyloid ridge of the humerus (Plate II, Fig. I).

Insertion: To the styloid process of the radius by a very slender tendon(PIate III, Fig. 2).

EXTENSOR CARPI RADIAIIS IONGUS AND BREVIS (LES RadiaUX Externes)

Origin: From the entire dorsal margin of the supracondyloid ridge of the humems distad of the Brachioradialis (Plate II, Fig. I).

Insertion: To the second and third metacarpals.

EXTENSOR INDICIS (Un Extenseur Exteme)

origin: From the posterior half of the ulna on its lateral surface and along the ulna in an oblique and. 
distad direction toward the radial side (Plate III, Fig. 2).

Insertion: To the pollex and the second digit. Its tendon bifurcates at the base of the second metacampal.

SUPINATOR (Ie Court Supinateur)

Origin: From the annular ligament and from the lateral head of the radius (PIate III, Fig. 2).

Insertion: To the medial side of the radius a few millimeters proximad of its distal extremity.

EXTENSOR POIIICIS BREVIS (Ie Grand Abducteur du Pouce)

Origin: From the proximal portion of the lateral surface of the ulna just distad of the semilunar notch. Also from the dorso-lateral surface of the radius and from the interosseous membrane (PIate III, Fig. 2).

Insertion: By strong flat tendon to the radial side of the base of the first metcarpal.

PRONATOR TERES (Ie Rond Pronatevir)

Origin: From the medial epicondyle of the humems (Plate II, Figs. I \& 2).

Insertion: To the medial aspect of the radius from the middle to its distal extremity.

EXTENSOR DIGITORUM COMMUNIS (I IEXttenseur Commun)

Origin: From the lateral supracondyloid ridge of the humems (Plate II, Fig. 2). 
Insertion: Its tendon passes beneath the transverse Iigament at the wrist and separates into four tendons to the phalanges of the second, third, fourth, and fifth digits.

EXTENSOR DIGITORUM LATERAIIS (Un Extenseur Externe)

Origin: From the proximal portion of the lateral epicondyle of the humerus (Plate II, Fig. 2).

Insertion: To the external side of the base of the third, fourth, and fifth digits. Its tendon passes beneath the transverse Iigament at the wrist and separates into three tendons.

EXTEISOR CARPI ULNARTS (Ie Gubital Posterieur)

Origin: From the lateral epicondyle of the humerus and from the ulna dorsal to the semilunar notch along the ulnar side of the forearm (PIate II, Fig. 2; Plate III, Fig. 3).

Insertion: To the uInar aspect of the base of the fifth metacarpal.

FTEXOR CARPI RADIAIIS (Ie Grand PaImaire)

Origin: From the medial epicondyle of the humerus (Plate II, Fig. 2).

Insertion: To the base of the second metacarpal. 
PALMARTS LONGUS (Ie Petit Palmaire)

Origin: From the dorsal aspect of the medial

epincondyle of the humerus (Plate II, Fig. 2).

Insertion: To the bases of the first phalanges of the second, third, fourth, and fifth digits.

FLEXOR CARPI ULNARIS (Ie Cubita] Anterieur)

Origin: From the median aspect of the distal

extremity of the humerus and from the dorso-medial

aspect of the olecranon to a point opposite the semilunar notch by two heads. Both heads join in the distal

third of the forearm (Plate III, Fig. I).

Insertion: To the pisiform bone.

FTEXOR DIGITORUM SUBIIMIS (Ies Flechisseurs Superficiels)

Origin: From the Flexor Digitorum Profundus.

Insertion: To the bases of the first phalanges of the first, second, third, and fourth digits.

FIEXOR DIGITORUM PROFUNDUS (Ie Flechisseur Profond des digits)

This muscle has five heads:

1. Origin: From the dorsal half of the medial surface

of the ulna between the proximal lip of the semilunar notch and the styloid process. 
Insertion: To the lateral border of the broad common tendon.

2. Origin: From the ventro-medial aspect of the radius distad of the point of insertion of the Biceps Brachii on the middle two-fourths of the radius. Also from the interosseous membrane.

Insertion: To the common tendon.

3. Origin: From the distal portion of the medial epicondyle of the humerus (Plate II, Fig.

Insertion: By a slender tendon to the radial side of the common tendon.

4. Origin: From the distal portion of the medial epicondyle of the humerus.

Insertion: To the common tendon. This tendon divides to insert to the bases of the terminal phalanges of all five digits.

PRONATOR QUADRATUS (Ie Carre Pronateur)

Origin:. From the distal third of the ulna (Plate III, Fig. 1).

Insertion: To the distal third of the radius. It fills the interosseous space between the two bones. 


\section{THE MUSCIES OF THE HAND}

The muscles of the hand include the Lumbricales, the Adductor Pollicis Brevis, the Flexor Pollicis Brevis, the Adductor Pollicis, the Interossei, the Adductor Digiti Secundi, the Adductor Digiti Quinti, the Flexor Digiti Quinti Brevis, and the Opponeus Digiti Quinti. These were not dissected at present bet were noted bty Alix (1876).

\section{MUSCIES OF THE HIP AND THIGH}

TENSOR FASCIAE IATAF (Ie Tenseur du Fascia Lata)

Origin: From the ventral border of the ilium

(Pliate VI, Fig. I).

Insertion: To the fasciae latae.

GIUTEUS MAXINUS (Ie Grand Fessier)

Origin: By fascia opposite to the sacral vertebrae and by fibers from the Gluteus Medius.

Insertion: To the most distal portion of the greater trochanter of the femur (Plate IV, Fig. 2).

GLUTEUS MEDIUS (Ie Moyen Fessier)

Origin: From the lateral aspect of the ilium and from fascia opposite to the lumbar vertebrae (Plate VI, Fig. I). 
Insertion: To the most proximal portion of the greater trochanter of the femur (Plate IV, Fig. 2).

GLUTEUS ININIMUS (Le Petit Fessier)

Origin: From the lateral aspect of the ilium (Plate VI, Fig. I).

Insertion: To the anterior margin of the greater trochanter of the femur (PIate IV, Fig. 2).

\section{PIRIFOFMIS (Ie PyramidaI)}

Origin: From the transverse process of the last sacral and first caudal vertebrae.

Insertion: To the greater trochanter of the femur (Plate IV, Fig. 2).

GENELIUS INFERIOR (Not named by AIix)

Origin: From the lateral surface of the ischium between the ischial spine and the tube rosity.

Insertion: To the trochanteric fossa.

GEIEIIUS SUPERIOR (Not named by Alix)

Origin: From the dorsal border of the ilium and the ischium(Blate VI, Fig. 1).

Insertion: To the trochanteric fossa (PIate IV, Figs. I \& 2). 
QUADRATUS FEMORIS (Ie Carme)

Origin: From the lateral surface of the ischium (PIate VI, Fig. 1).

Insertion: To the medial portion of the greater tuberosity of the femur (PIate IV, Fig. I).

OBTURATOR EXTERINS (I'Opturator Exterme)

Origin: From the pubis adjacent to the obturator. foramen (Plate VI, Fig. I).

Insertion: To the trochanteric fossa by tendon (Plate IV, Fig. I).

OBTURATOR INTERIUS (I'Obturator Inteme)

Origin: From the medial surface of the innominate. Insertion: To the trochanteric fossa with the gemelli muscles.

BICEPS FEMORIS (Le Biceps)

Origin: From the lateral aspect of the tuberosity of the ischium (PIate VI, Fig. I).

Insertion: To the lateral margin of the patella and to the anterior surface of the tibia (Plate V, Fig. I).

TENUISSIMUS (I'Accessoire Cocygien)

Origin: From the first caudal vertebra.

Insertion: It runs subjacent to the biceps and fuses with it. 
ADDUCTORS (IEs Adducteurs)

1. Origin: From the caudal portion of the isahial border and from the ramus of the ischium (Plate VI, Fig. I)

Insertion: To the medial condyle of the femur.

2. Origin: From the entire symphysis pubis. Insertion: To the proximal portion of the ventral surface of the femur and to the lesser trochanter of the femur (Plate IV, Fig. I).

3. Origin: From the caudal half of the pubis laterad of the symphysis. Insertion: To the lateral condyle of the femur.

\section{PECTINEALS (Les Pectines)}

Origin: By two slips from the ilio-pectineal

\section{eminence.}

Insertion: In two parts, to the femur with the third part of the adductor group (Plate VI, Fig. I).

RECTUS FEMORIS (Ie Droit Anterieur)

Origin: From the acetabular bone just craniad of the acetabulum (PIate VI, Fig. I).

Insertion: To the medio-doral surface of the patelia (Plate V, Fig. I). 
VASTUS IATERAIIS (Ie Vaste Exterme)

Origin: From the greater trochanter of the femur (Plate IV, Fig. 2).

Insertion: To the outer surface of the patella (Plate V, Fig. I).

VASTUS MEDIAIIS (Le Vaste Interne)

Origin: From the dorsal surpace of the femur at its proximal extremity (Plate IV, Fig. 2).

Insertion: To the medial margin of the patella.

VASTUS INTERMEDIUS (Not named by Alix)

Origin: From the proximal extremity of the femur on its dorsal surface, between the Vastus Medialis and the Vastus Lateralis muscles (Plate IV, Fig. 2).

Insertion: To the medial portion of the proximal border of the patelia (Plate V, Fig. I).

MUSCIES OF THE LOWER IEG AND FOOT

GASTROCNENIUS (IES Gastrocnemien)

Origin: By two heads. One from each condyle on the posterior face of the femur (PIate IV, Fig. I).

Insertion: To the proximal end of the calcaneus by the achilles tendon. The two heads fuse a feww millimeters distad of their origin. 


\section{PLANTARIS (Ie Plantaire)}

Origin: With the lateral head of the gastrocnemius from the lateral condyle on the posterior face of the femr (Plate IV, Fig. I).

Insertion: It is fused with the gastrocnemius and. mus over the calcaneus. It sends (from either side) an expansion to the calcaneus and then inserts to the Flexor Digitorum Brevis.

SOIFUS (Ie Soleaire)

Origin: By long slender tendon from the posterior face of the fibular head (Plate V, Fig. 2). Insertion: To the proximal end of the calcaneus.

POPITIEUS (Ie Poplite)

Origin: From the lateral epicondyle of the femur (PIate IV, Fig. I).

Insertion: To the postero-lateral surface on the proximal third of the tibia (Plate V, Fig. 2).

FIEXOR DIGITORUM LONGUS (Ie faisceau tibial du Flechisseur) Profound)

Origin: From the proximal half of the posterior surface of the tibia (Plate V, Fig. 2).

Insertion: Its tendon fuses with that of the Flexor Hallucis Longus. 
CAUDOFEMORAIIS (Ie Femoro Coccygien)

- Origin: From the first three caudal vertebrae.

Insertion: To the second quarter of the shaft of the femur on its postero-lateral surface (PIate IV, Fig. 1).

SEMITENDINOSUS (Ie Demi-tendineux)

Origin: From the apex of the tuberosity of the ischium (Plate VI, Fig. I).

Insertion: To the crest of the tibia (Plate $\mathrm{V}$, Fig. 1).

SEMIMEMBRANOSUS (Ie Demi-membranevx)

Origin: From the tuberosity of the ischium (PIate VI, Fig. 1).

Insertion: To the medial tuberosity of the tibia (Plate V, Fig. I).

SARTORIUS (Ie Couturier)

Origin: From the ventral half of the crest of the ilium (Plate VI, Fig. I).

Insertion: To the patella and distally to the anterior crest of the tibia (Plate V, Fig. I).

GRACIIIS (Ie Rectus Internus)

Origin: From the symphysis pubis (Plate VI, Fig. I). Insertion: To the anterior crest of the tibia (Plate V, Fig. I). 
FIEXOR HAJIUCIS LONGUS (Le faisceau peroneal du Flechisseur Profond)

Origin: From the posterior surface of the proximal three-fourths of the fibula and from the lateral surface of the posterior aspect of the tibia (Plate V, Fig. 2). Insertion: Its tendon unites to the tendon of the Flexor Longus Digitorum. The conjoined tendons give off five slips, one to each toe.

TIBIAIIS POSTERIOR (Ie Jambier Posterieur)

Origin: From the posterior surface of the tibia and from the postero-medial surface of the fjbular head (Plate V, Fig. 2).

Insertion: To the scaphoid and first cuneiforme bones by tendon.

PERONEUS LONGUS (Ie Long Peronier)

Origin: From the dorso-lateral aspect of the head. of the tibia (Plate V, Fig. 2).

Insertion: To the bases of the first and the fifth metatarsals.

PERONEUS TERTIUS (IE Peronier)

Origin: From the lateral aspect of the fibular shaft on its second quarter (Plate V, Fig. I). 
Insertion: To the dorsal surface of the second phalanx of the fifth digit where fusion occurs with the tendon of the Extensor Digitorum Longus.

\section{PERONEUS BREVIS (Ie Court Peronier)}

Origin: From the distal three-fourths of the lateral surface of the fibular shaft (Plate V, Fig. I). Insertion: To the lateral side of the base of the fifth metacarpal.

EXTENSOR DIGITORUM LONGUS ( Ie Commun Extenseur)

Origin: From the lateral epicondyle of the femur.

Insertion: By tendons to the dorsal surfaces of the baes of the second phalanges of the second to the fifth digits.

TIBIALIS ANTERIOR (Ie Jambier Anterieur)

Origin: From the lateral and the medial aspects of the tibia and the fibula respectively at their proximal extremities (Plate V, Fig. I). Insertion: To the medial side of the first metatarsal.

EXTENSOR DIGITORUM BREVIS (Ie Pedieux)

origin: From the dorsal surface of the calcaneus. 
Insertion: To the lateral sides of the

first to fourth digits at their bases.

FIEXOR DIGITORUM BREVIS (Ie Flexor Superficiel)

Origin: From the distal extremity of the Plantaris muscle.

Insertion: To the second phalanges of the second to the fifth digits.

ACCESSORIUS (Ie Chair Carre)

origin: From the ventral surface of the body and tubercle of the calcaneus.

Insertion: To the tendon of the Flexor Digitorum

\section{Iongus.}

The short muscles of the foot include the Lumbricales; the Calcaneometatarsalis; the Abductor Hallucis; the Adductor muscles, that is, one each for the hallux, index, and minimus; and a deeper layer of muscles consisting of a Flexor Brevis muscle; for each toe. These muscles have not been dissected in detail at present. 


\section{VASCUIAR SYSTEM}

The heart, which is enclosed in the pericardial sac, lies in the middle mediastinal cavity in the area bounded by the fourth to the eighth ribs. From its left ventricle arises the aorta which arches and mins caudalyy slightly to the left of the dorsal midiine. The aorta, from its base on the ventral surface, gives off the coronary arteries to the auricular and ventricular walls of the heart. From the convexity of the aortic arch the innominate and the external subclavian arteries are given off. Opposite to the point of emergence of these vessels can be seen the ligament of Botallus which extends from the pulmonary artery to the aorta. Other branches of the thoracic aorta include the intercostal, the bronchial, the esophageal, and the lumbar arteries.

From the abdominal aorta there arise in antero-posterior order: the coeliac axis, the phrenic artery, the superior mesenteric artery, the adrenolumbar arteries, the renal arteries, the genital arteries, the inferior mesenteric artery, and the ilio-lumbar arteries. The aorta gives; off lumbar arteries to the body at regular intervals from the diaphragm to the point of origin of 
the external iliac arteries which also arise from the aorta. The latter vessels supply the hindlimbs. The internal iliacs arise caudad of the external iliac arteries and supply the pelvic viscera and the muscles of the innominate region. The aorta then continues into the pelvic region as the median sacral artery. The innominate artery, which is proportionately longer than that of the cat, gives off a small mediastinal artery before it divides to form the right and left conmon carotid arteries. The right common carotid fives off a vessel which bifurcates to form the right subclavian and the internal mamary arteries. The arrangement of all the aforementioned vessels in the ferret is similar to that in the domestic cat with two exceptions: In the cat the phrenic artery usually arises from the adrenolumbar artery but in the ferret it was found to come off the first lumbar artery. In the ferret the innominate artery is proportionately longer than in the domestic cat. This is correlated. with the former's elongated neck. 


\section{DIGESTIVE SYSTEM}

The ferret's digestive system is typically that of a carnivorous animal. However, it differs from that of the cat in several respects. The structure of the teeth of both of these forms is similar but there is a difference in their number. This has been discussed previously in connection with the skeletal structures. Because of the ferret's long neck the esophagus is proportionately longer than that of the cat. The colic caecum, which is small or wanting in monotremes, flesheating marsupials, carnivores, and insectivores, is almost negligible in size in Mustela putorius. That of Felis domesticus is relatively larger. From the relative sizes of the colic caeca of these animals it would appear that the ferret is more carnivorous than the cat. The ferret's liver is relatively larger than the cat's and consists of six minor lobes (the caudate or Spigelian lobe being represented by two dorsal lobes) whereas in the cat it is composed of only five lobes. In Felis domesticus the right median lobe is known as the cystic lobe because it contains the gall-bladder. The ferret's right median lobe does not deserve the 
adjective 'cystic' because the gall-bladder lies between the right median and the right lateral lobes, and not in the cystic lobe of the liver as in the domestic cat. 


\section{SUMMARY}

1. The available literature concerning the ferret has been reviewed.

2. The skeletal structures of the ferret have been compared with those of the domestic cat. It was found that:

(a) Because of the stmucture and the relations of the orbital and temporal fossae, and the smaller braincase in the ferret, the latter's skull is the more primitive.

(b) The dental formulae of the two animals are different, and the diastema is absent from the ferret.

(c) The scapula of the ferret differs in shape from that of the domestic cat. An additional angle of the scapula, not present in the cat has been described.

(d) The clavicle was found to be rudimentary in the ferret. In this respect the ferret is more specialized than the cat.

(e) The skeletal structures of the extremities of the ferret and the cat were found to differ but slightly in form and in relative length. 
(f) The vertebral columns of the domestic cat and of the ferret are similar in structure. A foramen, not present in the cat, was described as the lateral transverse foramen.

(g) It is concluded that the stmucture of the skulls is the most variable and therefore of greatest value in the classification of these camivores.

3. The origins and the insertions of the muscles of the ferret have been noted and the extent of their attachment has been indicated on the outline drawings of the skeleton.

4. The musculature of the ferret has been compred with closely related camivores, especially the domestic cat. It was noted that the Triceps Brachii muscle of the ferret has four heads, whereas that of the cat and other carnivores has only three heads. The absence of the Coracobrachialis muscle in the ferret was noted. It was found that the Sternomastoid muscles of the ferret fuse in the midline. Those of the cat remain separate from each other. The complete absence of the Serratus Posterior Inferior muscle was noted. It was observed that the Rectus Capitis Posterior Minor muscle is represented by a few fibers in the ferret but it is a distinct triangular bundle in the domestic cat. It was 
found that the muscles in the shoulder region have a slightly altered arrangement because of the reduction of the clavicle in the ferret.

5. It was found that the vascular systems of the cat and the ferret are similar with two exceptions: In the cat the phrenic artery usually arises from the adrenolumbar artery, but in the ferret it was found to come off from the first lumbar artery. In the ferret the innominate artery is proportionately longer than in the domestic cat.

6. The digestive systems of these two animals were found to differ in several respects. The esophagus of the ferret is proportionately longer. The colic caecum of the ferret is relatively smaller than that of the cat. The liver is relatively larger in the ferret than in the cat. It consists of six minor lobes in the former and of only five lobes in the latter. The gall-gladder was found to be situated. between the right median and the right lateral lobes of the ferret's liver and not in the cystic lobe as in the cat. 

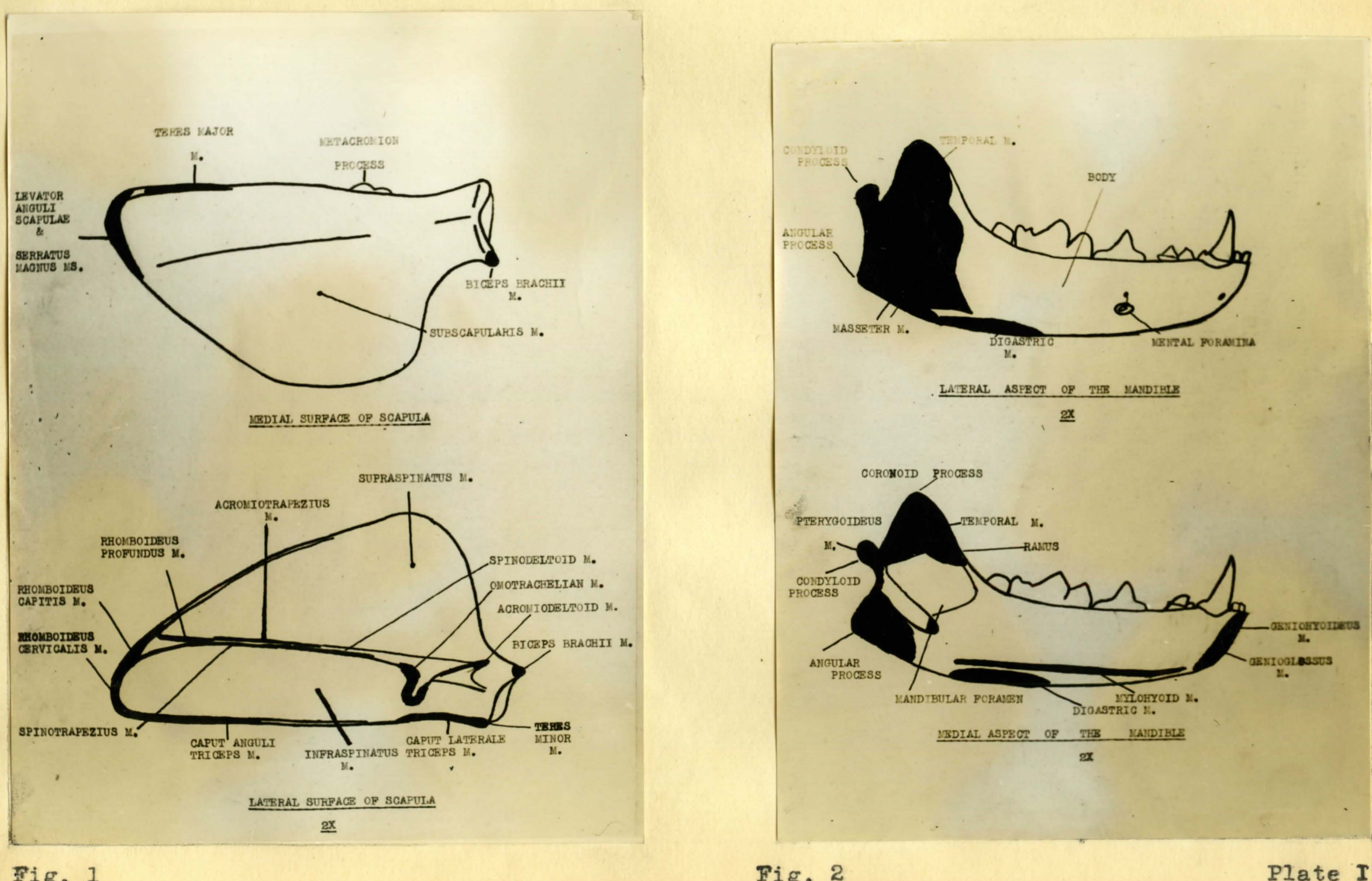


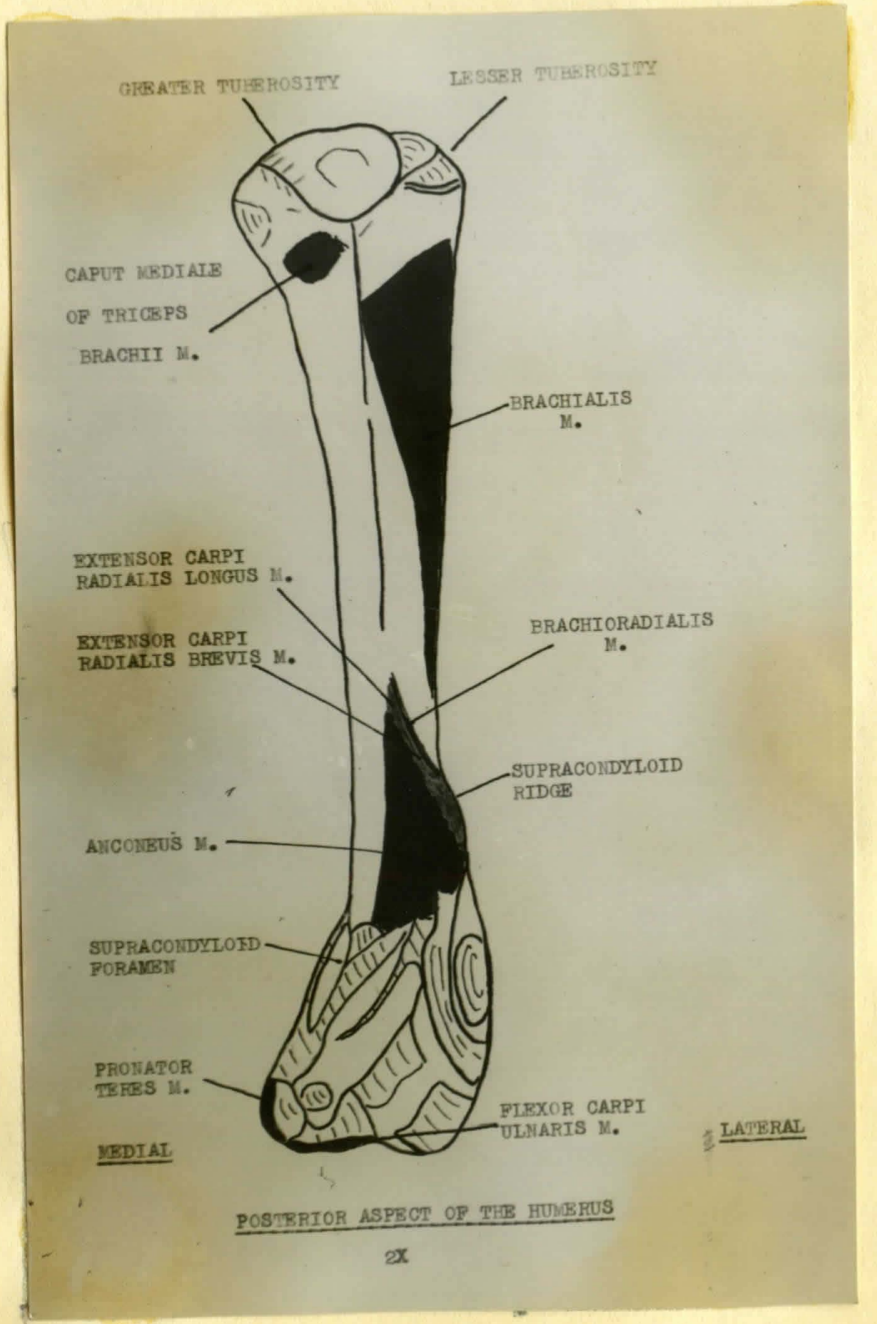

Pig. 1

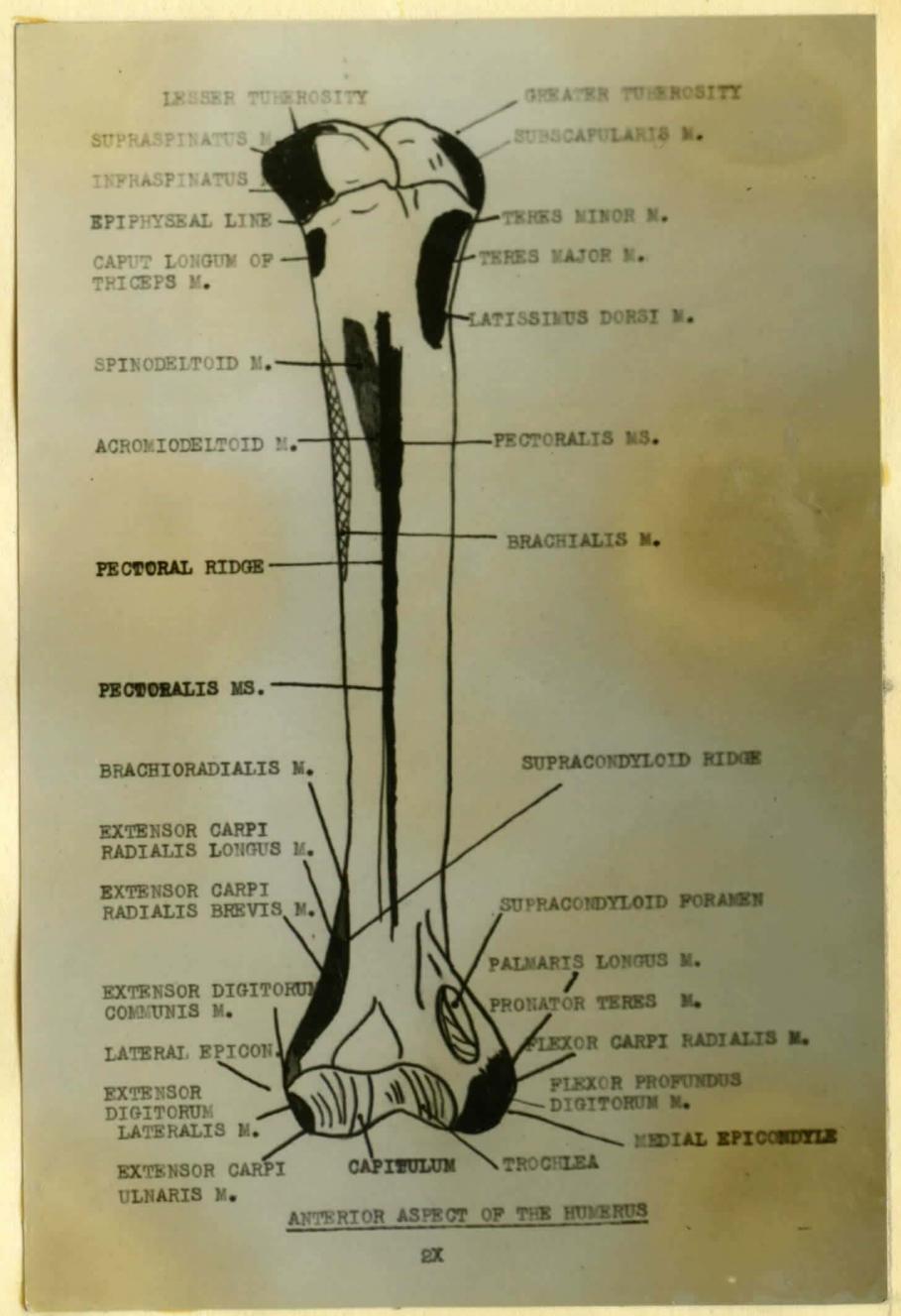

Fig. 2 


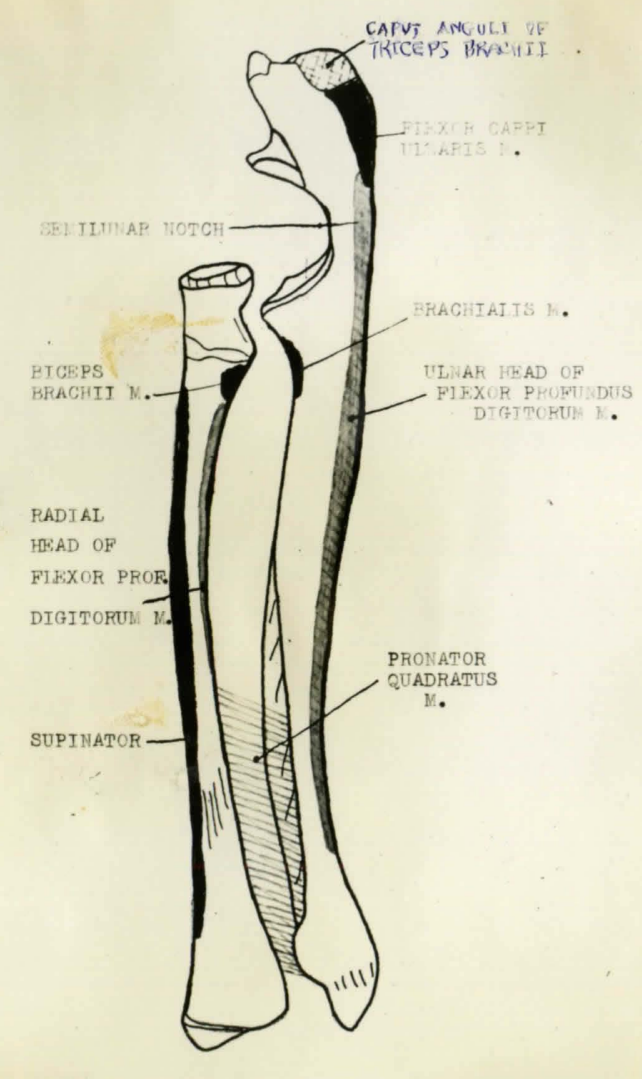

IEDTAI ASPECT OF THE RADTIS \& TIE ULNA

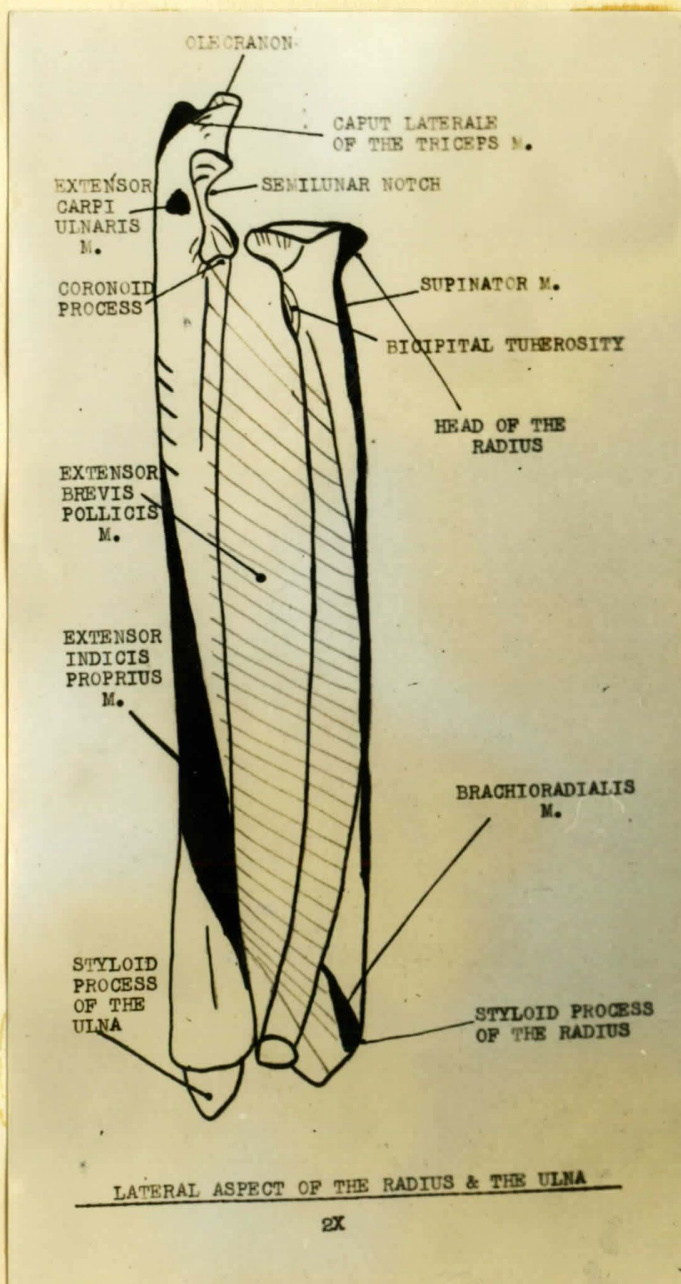

Fig. I

Fig.2

Plate III. 

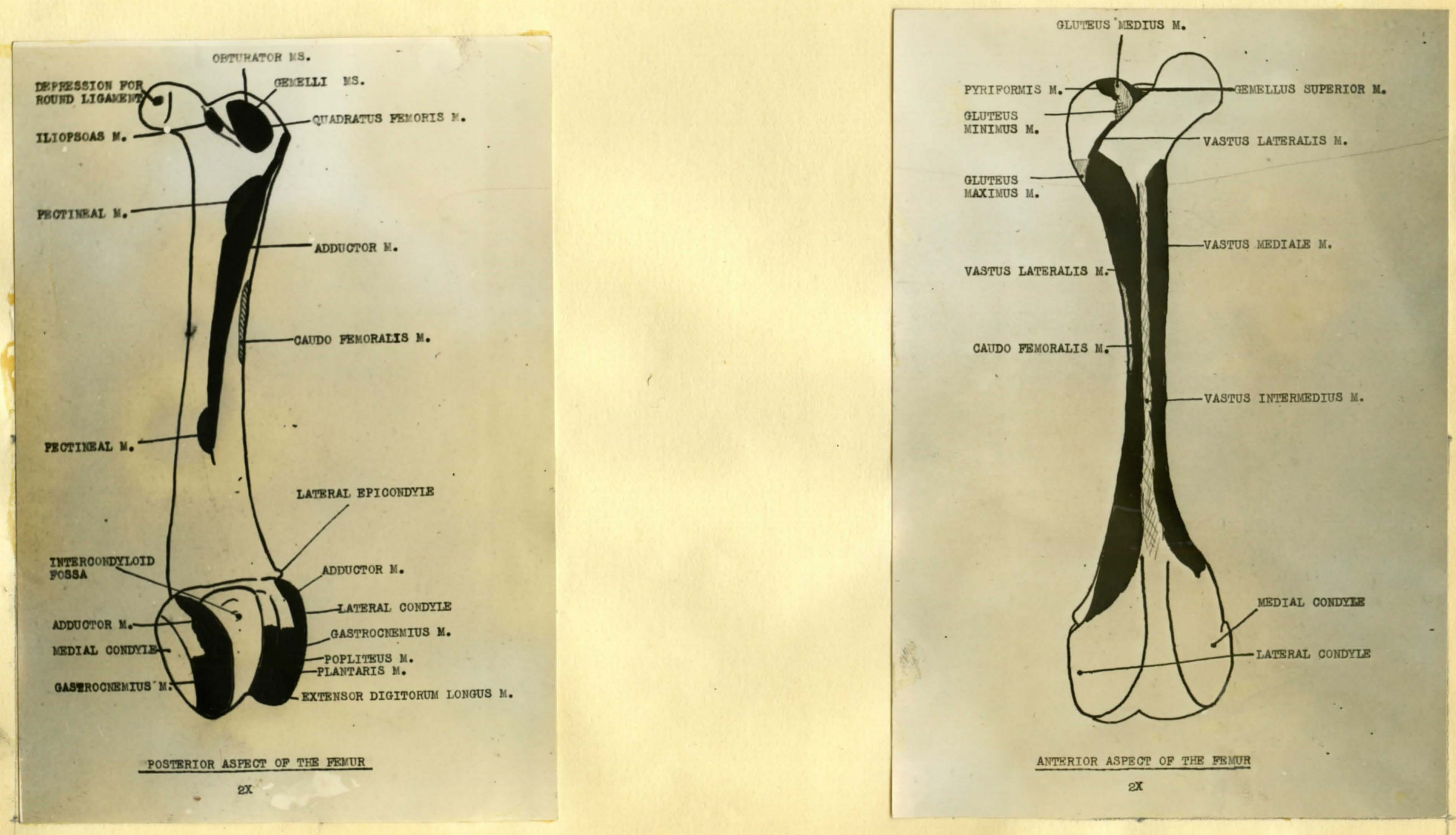

Fig. ]. 

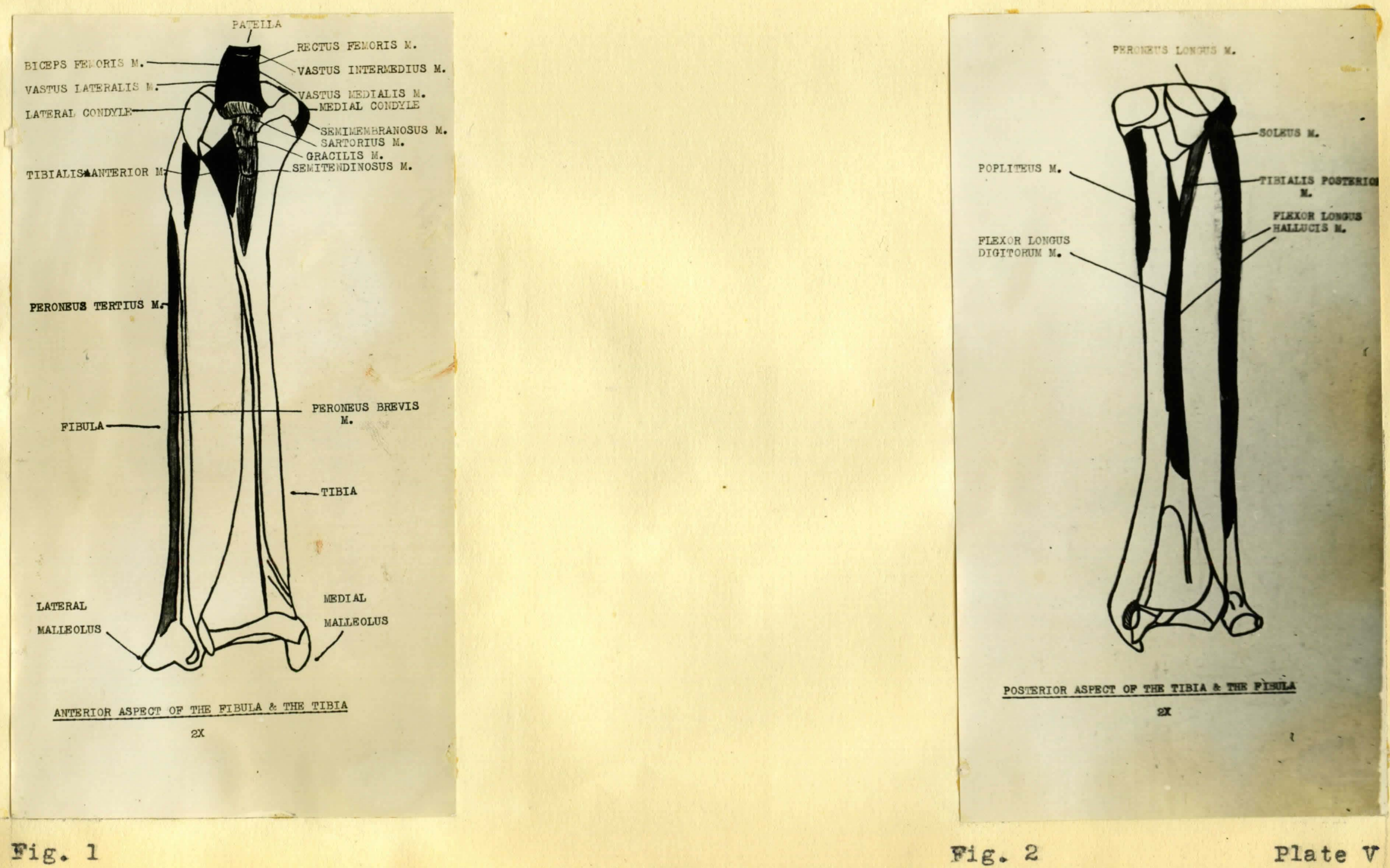

Iig. 1

Fig. 2

Plate V 


$$
80
$$




\section{BIBIIOGRAPHY}

Alix, E. 1876. Memoire sur la Myologie du Putois. Jour. de Zoologie. Paris. Vol. 5, pp. 152-188.

Allanson, M. 1932. Reproductive Processes of Certain Mammals. III The Reproductive Cycle In the Male Ferret. Proc. Roy. Soc. B, Vol. 110, pp. $295-310$.

Bissonnette, T. H. 1933. Modification of Mammalian Sexual Cycle. Iight and Sexual Cycles in Starlings and Ferrets, Quart. Rev. Biol., Vol. 8, pp. 201-208. Bissonnette, T. H. 1935a. Modification of Mammalian Sexual Cycles. Effects Upon Young Male Ferrets of Constant Eight and One-half Hour Days and Six Hours of Illumination After Dark Between November and June. Biol. Bull., Vol. 68, po. 300-313.

Delling, T. 1931. Distemper in the Fitch. Vet. Record, Vol. 11, pp. 1051-1052.

Dunken, G.W., and P. P. Laidlaw, and A. S. Griffith. 1929. A Note on Tuberculosis in the Ferret. Jour. Comp. Path. and Therap., Vol. 42, pp. 46-49.

Edwards, M. 1853. Notions Preliminaires de Zoologie. Victor Masson. Paris.

Everitt, N. 1897. Ferrets. A. and C. Black. Iondon. 
Gray, M. 1930. Anatomy of the Human Body. 22nd Edition. pp. 443. Lea and Febiger, N.Y.

Harding, A.R. 1915. Ferret Facts and Fancies.

Columbus, Ohio.

Hill, M., and A.S. Parkes. 1930. The Relation Between the Anterior Pituitary and the Gonads; Induction of Ovulation in the Ferret. Proc. Roy. Soc. B, Vol. 107, pp. 34-49.

Laidlaw, P.P., and G.W. Dunkin. 1928. Immunization of Ferrets Against Dog Distemper. Jour. Comp. Path. and Therap., Vol. 4l, pp. 1-17 and $209-227$

Mainland, D. 1930. The Early Development of the Eerret; The Pronuclei. Jour. Anat. Vol. 64, pp. $262-287$.

Mainland, D. 1931a. The Measurement of Ferret Pronuclei. Trans. Roy. Soc. (Canada), Ser. 3, Vol. 25, pp. $1-10$.

Mainland, D. 1931b. The Volumes of Ferret Ova with Special Reference to Methods of Determination. Anat. Rec., Vol. 50, po. 53-83. Mainland, D. 1931c. The Sizes of Ferret Promuclei. Anat. Rec., Vol. 49, pp. 103-120. 
Mainland, D. 1931d. A Quantitative Study of the Polar

Body of the Ferret. Amer. Jour. Anat., Vol. 47. pp. $195-240$.

Mainland, D. 193le. Early Development of the Ferret; The Cytoplasm. Jour. Anat,, Vol. 65. pp. 411-426. Mainland, D. 1932. Early Development of the Ferret; The Zona Pellucida, Zona Granulosa, and Associated Structures. Jour. Anat., Vol. 66, pp. 596-601.

Marshall, F.H.A. 1904. Sexual Cycle of the Female Ferret. Quart. Jour. Micr. Sci., Vol. 48, pp. 323-346. Marshall, F.H.A. 1922. Physiology of Reproduction. Iongmans Green and Co., London.

Marshall, F.H.A., and M. Hammond, 1930. Sexual Cycle of the Female Ferret. Proc. Roy.Soc. B, Vol. 105. pp. 607-628.

Pitt, F. 1921. Genetic Behavior of Certain Characteristics of the Ferret. Jour. of Genetics (Iondon), Vol. 11, pp. 99-114.

Reighard, J., and H.S. Jennings. 1935. Anatomy of the Cat. Ed. 3, revised; Henry Holt and Company.

Robinson, A. 1893. Observations on the Development of the Common Ferret. Anat. Anz., Vol. 8, pp. 116120. 
61.

Robinson, A. 1918. Formation, Rupture, and closure of Ovarian Follicles in Ferrets. Trans. Roy. Soc. (Edinburgh), Vol. 52, pp. 303-321. Smith, W., C. Andrewes, and P.P. Laidlaw. 1935.

Immunization of Ferrets to Influenza. Brit. Jour. Exper. Path. Vol. 16, pp. 29l-302. Windle, B.C.A., and F.G. Parsons. 1897. On the Anatomy of the Terrestrial Carnivora. Proc. Zool. Soc. (London) pp. 370-409.

Windle, B.C.A., and F.G.Parsons 1898. On the Anatomy of the Terrestrial Carnivora. Proc. Zool. Soc. (London) pp. 152-186. 